\title{
U.V Spectroscopic study of Benzylidine p- toluenesulphonomide Schiff- bases in absolute methanol - Direct determination of trace amounts
}

\author{
Amel G. Abed \\ Department of Chemistry / College of Science \\ Mosul University
}

Received

14 / 12 / 2010
Accepted

09 / 05 / 2011

\section{المالخص}

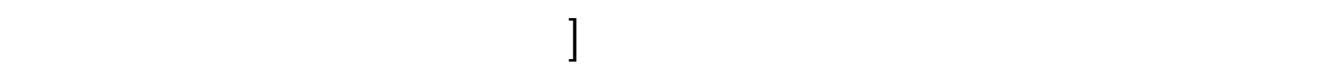

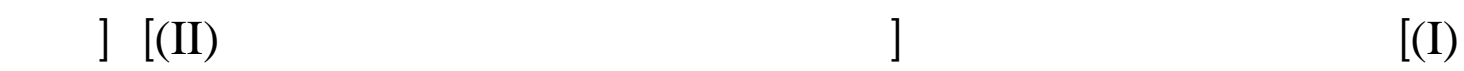

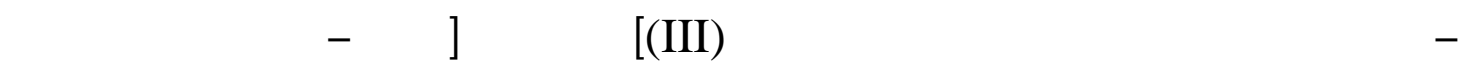

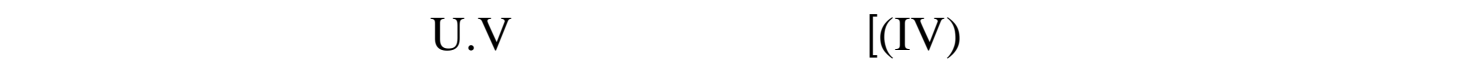

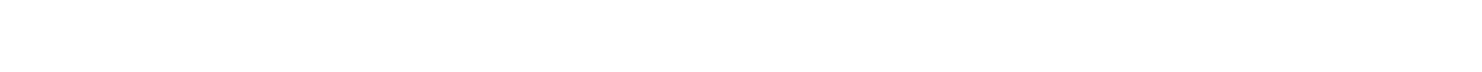

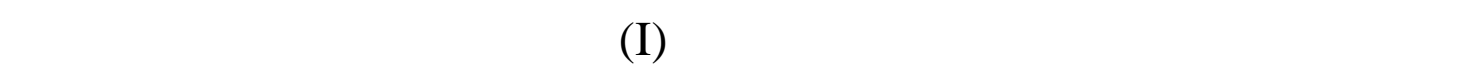

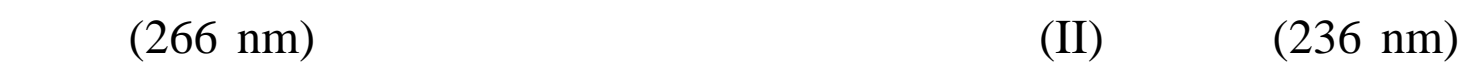

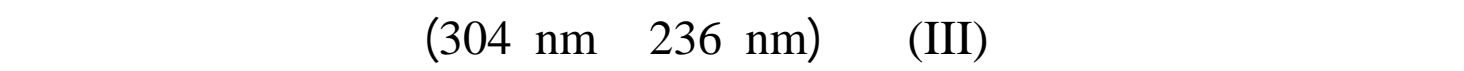
عند الطول الموجية (IV)

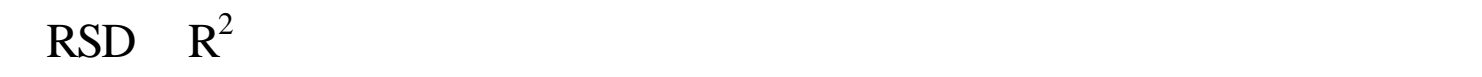

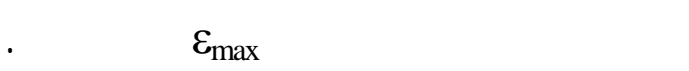

\section{Abstract}

The study including preparation of Schiff's Bases compounds, Benzylidine p-toluenesulphonamide (I), p-nitrobenzylidine-ptoluenesulphonamide 1,6-dichlorobenz-ylidine $\mathrm{p}-$ toluenesulphonamide (III), 3,4-dimethoxybenzylidine ptoluenesulphonamide (IV) and have been studied by U.V spectrophotometry in absolute methanol which gives bands at $(236 \mathrm{~nm})$ for compound (I), (266 nm) for compound (II), (236 \& 304nm) for compound (III) and (236, $274 \& 308 \mathrm{~nm}$ ) for compound (IV).

The direct determination limit was estimated through the plot of the molar concentration against the absorbance and $\mathrm{R}^{2}$, RSD and $\varepsilon_{\max }$ for each was calculated. 


\section{Introduction}

Schiff Bases are a biologically important compounds due to their antitumor and carcinostatic activities[1], the biological activity of Schiff bases has application which is attributed to the formation of stable complexes with transition metals presents in the living cell[2], Schiff bases known to exhibit a wide variety of pharmacological properties such as antiflammatory[3] and antimalarial[4]. The medical field that Schiff Bases used are selective in the metabolic synthesis of amino acids since they act as a thyroid human antigen [5]. Synthesis and characterization of metal complexes of Schiff base have been studied by Derebe, Raju and Retta [6], they found that the complexes of $\mathrm{Mn}(\mathrm{II}), \mathrm{Fe}(\mathrm{II}), \mathrm{Co}(\mathrm{II}), \mathrm{Ni}(\mathrm{II})$ and $\mathrm{Zn}(\mathrm{II})$ with an intermediate Schiff base derived from ninhydrin and $\alpha$, L-alanine were successfully synthesized. All complexes were characterized by molar conductance, magnetic susceptibility, infrared and electronic spectral studies. UV spectrophotometric method were used for the quantification of Schiff bases [7,8]. Siddappa and his group found two simple, sensitive and reproducible spectrophotometric methods for the determination of Metronidazol either in pure form or as tablets[9], Beer's law was obeyed in the concentration ranges 10 to $65 \mu \mathrm{g} \mathrm{ml}^{-1}$ and 5 to 40 $\mu \mathrm{g} \mathrm{ml}^{-1}$ with a limit of detection (LOD) of $0.080 \mu \mathrm{g} \mathrm{ml}^{-1}$ and $0.090 \mu \mathrm{g} \mathrm{ml}$

for the vanillin and p-dimethylaminobenzaldehyde methods respectively. The mean percentage recoveries were found to be $100.05 \pm$ 0.37 and $99.01 \pm 0.76$ for the two methods respectively. The direct U.V spectrophotometric study of some organic compounds (ester) in different solvents were also recorded [10].

Spectrophotometric methods have been used for the study of various compounds, such as many ortho-substituted phenols[11], some new 1,3 Benzoxaziens are characterized by their strong Hydrogen bonds[12] (study of their spectra in the infrared, U.V-Visible \& Mass fragmentation), studies for Schiff bases derived from 4,4-Dimethyl-3oxovaleraldehyde, acetyl acetone and benzoyl acetone were also carried out[13].

This work deals with the preparation of biologically important Schiff bases [5] [benzylidine p-toluensesulphonamide, (I)] and its three substituted [p-Nitrobenzylidine-p-toluenesulphonamide, (II)], [1,6dichlorobenzylidine p-toluenesulphonamide, (III)] and [3,4-dimethoxy benzylidine p-toluenesulphonamide, (IV)]. The U.V spectra have been measured and the absorption maximum for compounds were determined in absolute methanol, and quantification was accomplished according to these absorptions.

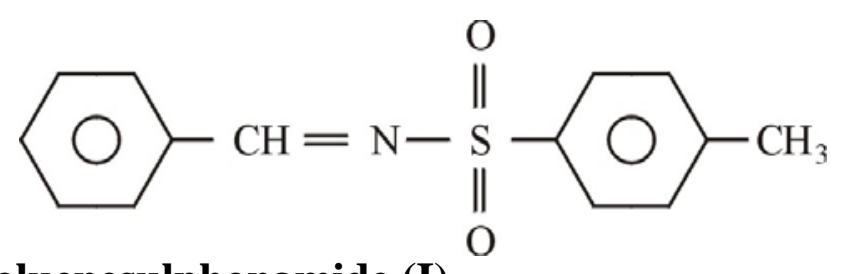

Benzylidine p-toluenesulphonamide (I) 


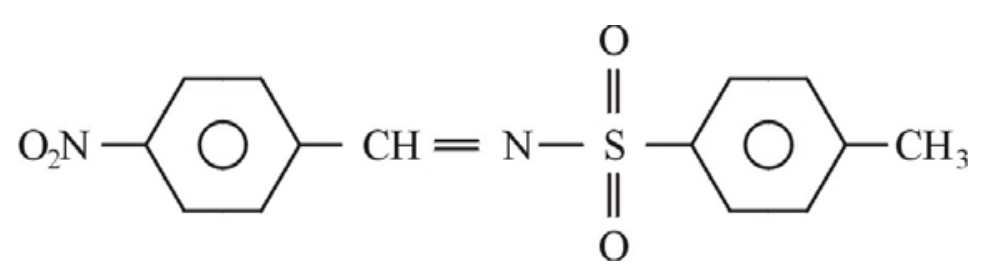

p-Nitrobenzylidine p-toluenesulphonamide (II)

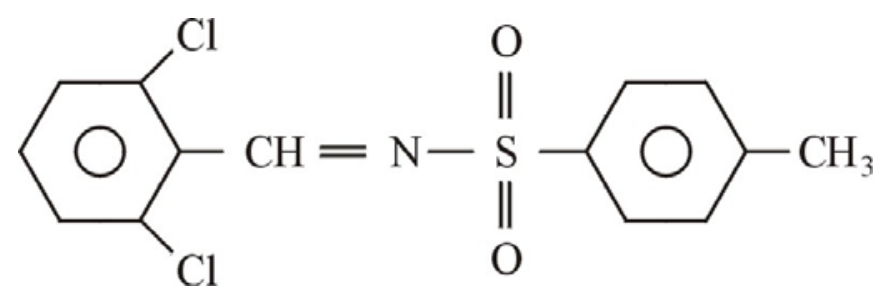

1,6-dichlorobenzylidine p-toluenesulphonamide (III)<smiles>COc1ccc(C=NS(=O)(=O)c2ccc(C)cc2)cc1OC</smiles>

3,4-dimethoxybenzylidine p-toluenesulphonamide (IV)

\section{Experimental}

Materials:

All aldehydes [benzaldehyde, 4-nitrobenzaldehyde, 2,6 dichloro benzaldehyde and 3,4 dimethoxy benzaldehyde] are of pure type and were used as freshly distilled for liquid phase.

p-toluenesulphonamide obtained from Fluka, absolute methanol obtained from Hopkin and Williams.

\section{Synthesis of compound (I-IV):}

To a solution of aromatic aldehyde $(0.02$ mole $)$ in $(30 \mathrm{ml})$ of methanol (99.5\%), p-toluenesulphonamide (0.02 mole) was added. The reaction mixture was refluxed for 24 hours, the solvent was then evaporated under vacuum and solid was collected and recrystallized from xylene [5,14].

The researches have shown that the reaction between ptoluenesulphonamide and the compound of aldehyde could be activated [15].<smiles></smiles>

p-toluenesulphonamide

Arylidine p-toluenesulphonamide

$$
\text { [R = alkyl or aryl group ] }
$$


Also an amine with suitable substituents easily reacts with aromatic aldehydes and cyclic ketones [16, 17].

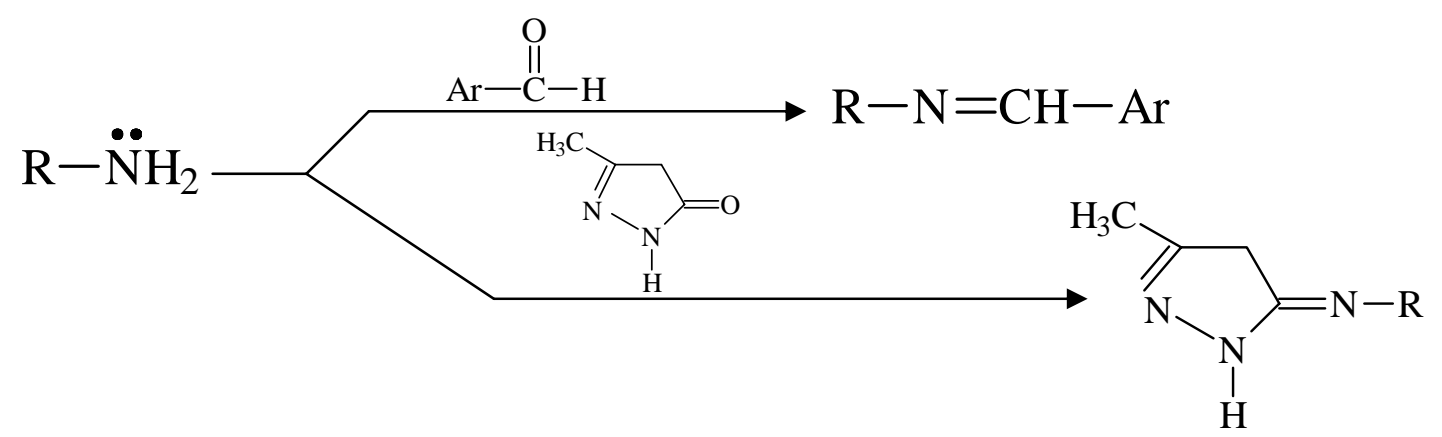

The physical and spectral properties of compounds (I-IV) were studied, the results are shown in table (1).

Table (1): Physical and spectral properties of compounds (I-IV)

\begin{tabular}{|c|c|c|c|c|c|c|}
\hline \multirow{2}{*}{ Compound } & M.P $\left({ }^{\circ} \mathbf{C}\right)$ & $\begin{array}{c}\text { Molecular } \\
\text { formula }\end{array}$ & Colour & \multicolumn{3}{|c|}{ I.R (KBr) $\left.v \mathbf{( c m}^{-\mathbf{1}}\right)$} \\
\cline { 4 - 7 } & $128-130$ & $\mathrm{C}_{14} \mathrm{H}_{13} \mathrm{NO}_{2} \mathrm{~S}$ & $\begin{array}{c}\text { Pale brown } \\
\text { plates }\end{array}$ & 1597 & $\begin{array}{c}\text { asym 1326; } \\
\text { sym 1151 }\end{array}$ & --- \\
\hline I & $104-105$ & $\mathrm{C}_{14} \mathrm{H}_{12} \mathrm{~N}_{2} \mathrm{O}_{4} \mathrm{~S}$ & $\begin{array}{c}\text { Brown- } \\
\text { Yellow } \\
\text { Powder }\end{array}$ & 1597 & $\begin{array}{c}\text { asym 1347; } \\
\text { sym 1160 }\end{array}$ & $\begin{array}{c}\mathrm{NO}_{2} \\
\text { asym 1524; } \\
\text { sym 1300 }\end{array}$ \\
\hline II & $64-67$ & $\mathrm{C}_{14} \mathrm{H}_{11} \mathrm{Cl}_{2} \mathrm{NO}_{2} \mathrm{~S}$ & $\begin{array}{c}\text { Pale } \\
\text { yellow } \\
\text { powder }\end{array}$ & 1578 & $\begin{array}{c}\text { asym 1328; } \\
\text { sym 1154 }\end{array}$ & --- \\
\hline III & $113-116$ & $\mathrm{C}_{16} \mathrm{H}_{17} \mathrm{NO}_{4} \mathrm{~S}$ & $\begin{array}{c}\text { Yellow- } \\
\text { Greenish } \\
\text { powder }\end{array}$ & 1576 & $\begin{array}{c}\text { asym 1326; } \\
\text { sym 1151 }\end{array}$ & $\begin{array}{c}\text { C-O-C } \\
1303 \text { asym }\end{array}$ \\
\hline IV & &
\end{tabular}

The compounds (I-IV) were identified by I.R spectra these compounds showed characteristic absorption band at (1597-1576 $\left.\mathrm{cm}^{-1}\right)$ indicating the presence of $(\mathrm{C}=\mathrm{N})$ group and they showed two types of vibrating modes for $\left(\mathrm{SO}_{2}\right)$ group asymmetric at $\left(1347-1326 \mathrm{~cm}^{-1}\right)$ and symmetric at $\left(1160-1150 \mathrm{~cm}^{-1}\right)$.

\section{Instrumentation:}

The ultraviolet absorption spectra were recorded with UV-Visible spectrophot-ometer type Shimadzu, UV-1650 pc, using Silica cell $1 \times 1 \times 3$ $\mathrm{cm}$.

\section{Measurements:}

Stock solution $\left(10^{-3} \mathrm{M}\right)$ of each of the compounds (I-IV) was freshly prepared by dissolving appropriate weight of the corresponding compound in absolute methanol. Other solutions $\left(10^{-4} \mathrm{M}, 10^{-5} \mathrm{M}\right.$ and $10^{-6} \mathrm{M}$ ) were prepared from stock solution by appropriate dilution. The UV spectra of each compound were recorded at a range of concentrations $\left(6 \times 10^{-6}-3 \times 10^{-4} \mathrm{M}\right)$. 


\section{Results and Discussion}

The UV absorption spectra, using different concentrations of (benzylidine p-toluenesulphonamide) (I) in absolute methanol, were recorded and showed absorption maximum at (236nm) with $\varepsilon_{\max }=4971.4$ lit. mole ${ }^{-1} . \mathrm{cm}^{-1}$ (Fig.1), (table 2).

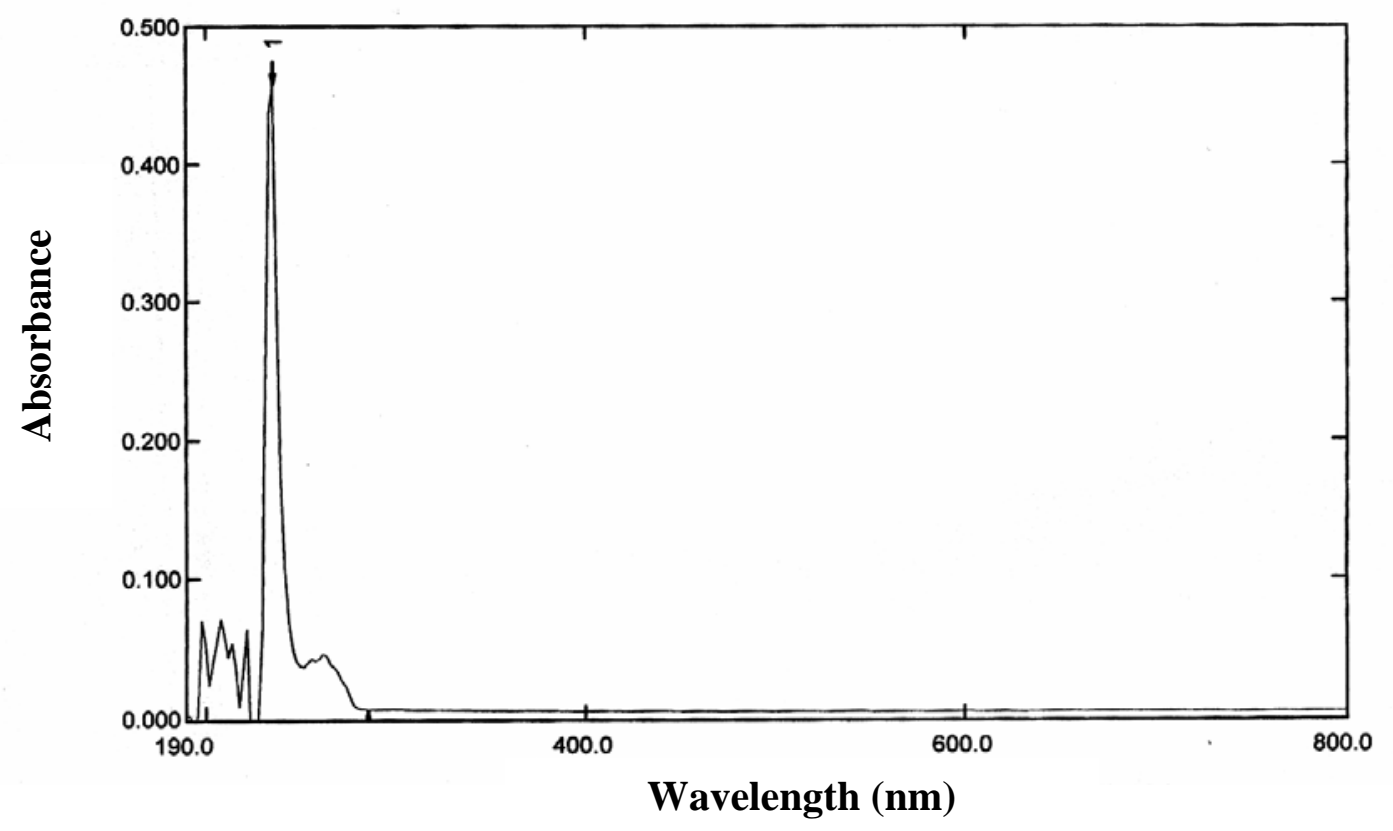

Figure (1): The U.V spectrum of $\left(1 \times 10^{-4} \mathrm{M}\right)$ of benzylidine $\mathrm{p}$ toluenesulphonamide in absolute methanol

Table (2): The absorbance of different concentrations of compound (I) in absolute methanol at $(236 \mathrm{~nm})$

\begin{tabular}{|c|c|}
\hline Absorbance & Concentration (M) \\
\hline 0.079 & $6 \times 10^{-6}$ \\
\hline 0.063 & $7 \times 10^{-6}$ \\
\hline 0.074 & $8 \times 10^{-6}$ \\
\hline 0.110 & $9 \times 10^{-6}$ \\
\hline 0.158 & $2 \times 10^{-5}$ \\
\hline 0.162 & $3 \times 10^{-5}$ \\
\hline 0.265 & $5 \times 10^{-5}$ \\
\hline 0.348 & $7 \times 10^{-5}$ \\
\hline 0.420 & $9 \times 10^{-5}$ \\
\hline 0.457 & $1 \times 10^{-4}$ \\
\hline
\end{tabular}

The plot of the absorbance against the molar concentration (Fig. 2) result in a straight line obeying the Beer's Lambert law within a range of concentrations $\left(6 \times 10^{-6}-1 \times 10^{-4} \mathrm{M}\right)$, with determination limits (1.5-25.9 $\left.\mu \mathrm{g} \mathrm{m}^{-1}\right)$ and $\mathrm{R}^{2}=(0.9911)$, $\mathrm{RSD}=(0.8 \%)$. 


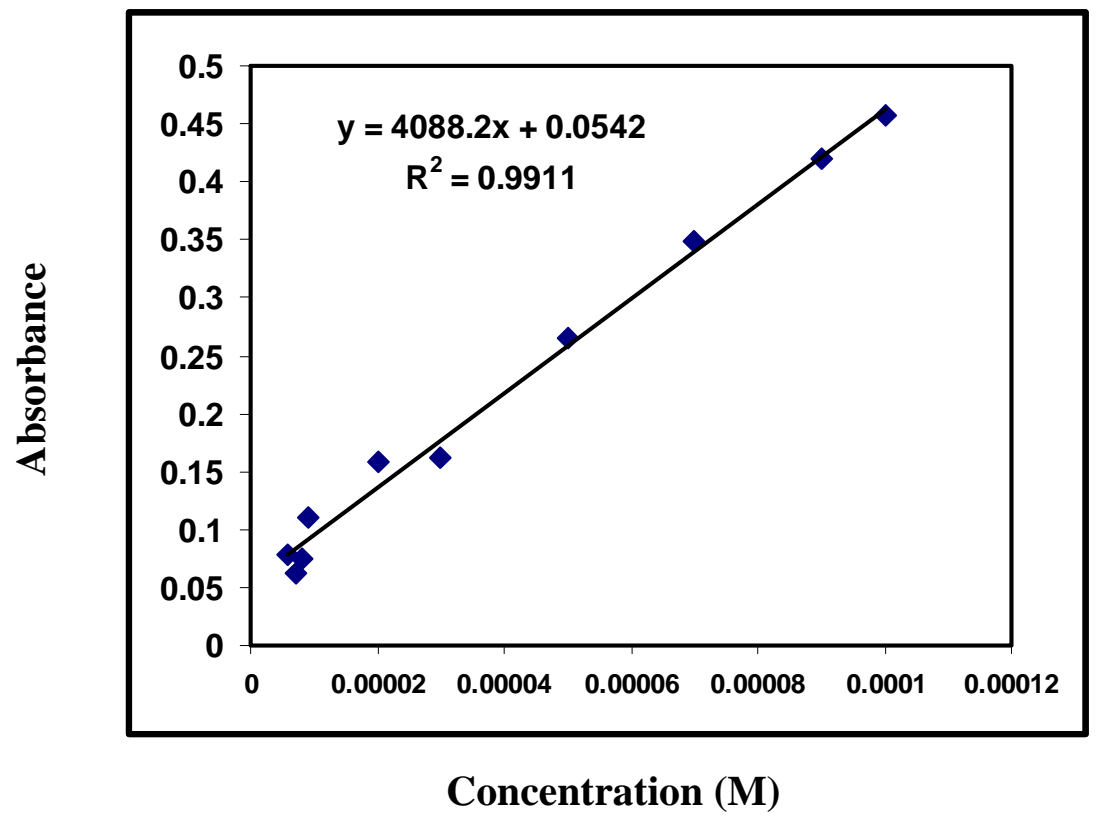

Figure (2): The relationship between absorbance and molar concentration for compound (I)

The U.V absorption spectra was also recorded for ptoluenesulphonamide (Fig. 3) and shows two peaks at (238nm) and (262nm).

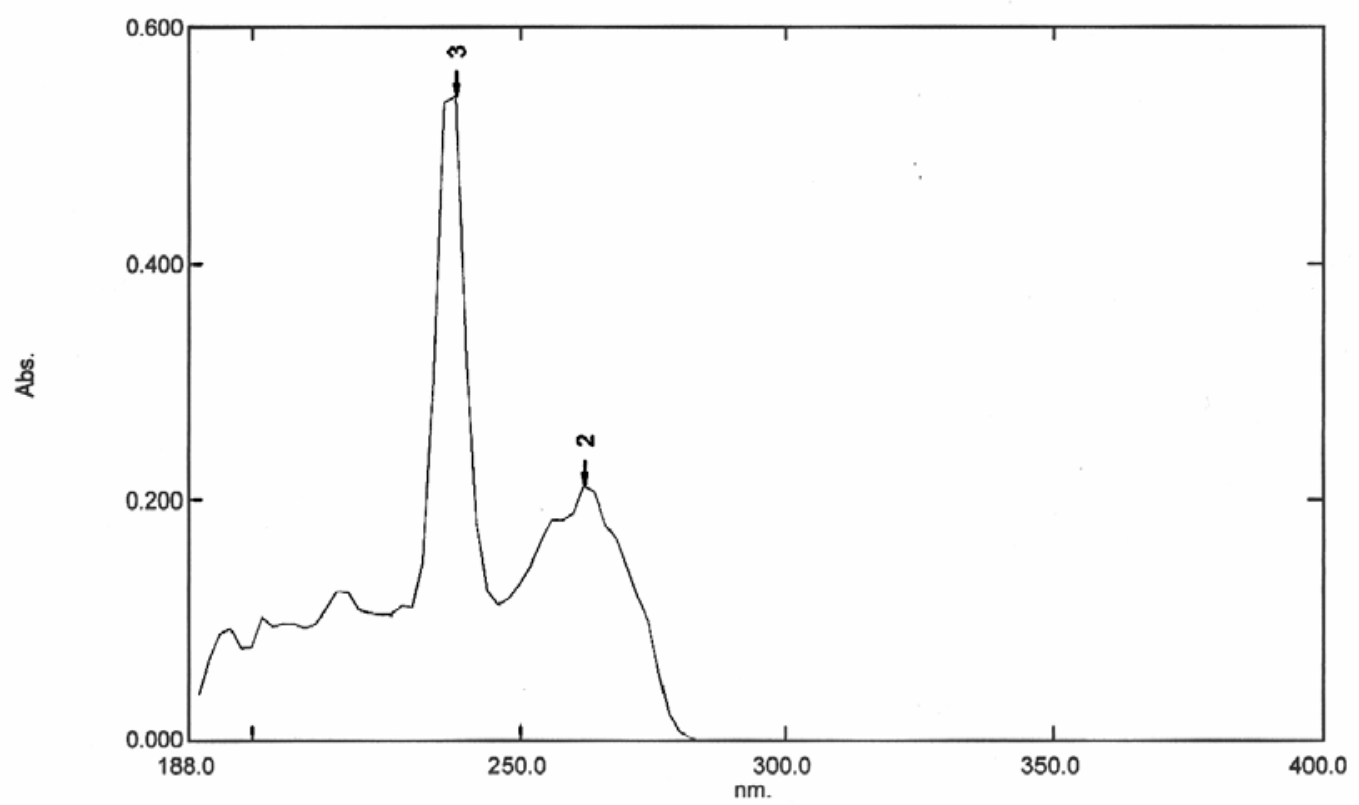

Figure (3): The U.V spectrum of $\left(7 \times 10^{-4} \mathrm{M}\right)$ of p-toluenesulphonamide in absolute methanol

The UV absorption spectra of (p-nitrobenzylidine p-toluenesulphonamide) compound (II) was recorded (Fig. 4) and shows absorption maximum at (266 nm) with $\varepsilon_{\max }=17930$, (table 3). 


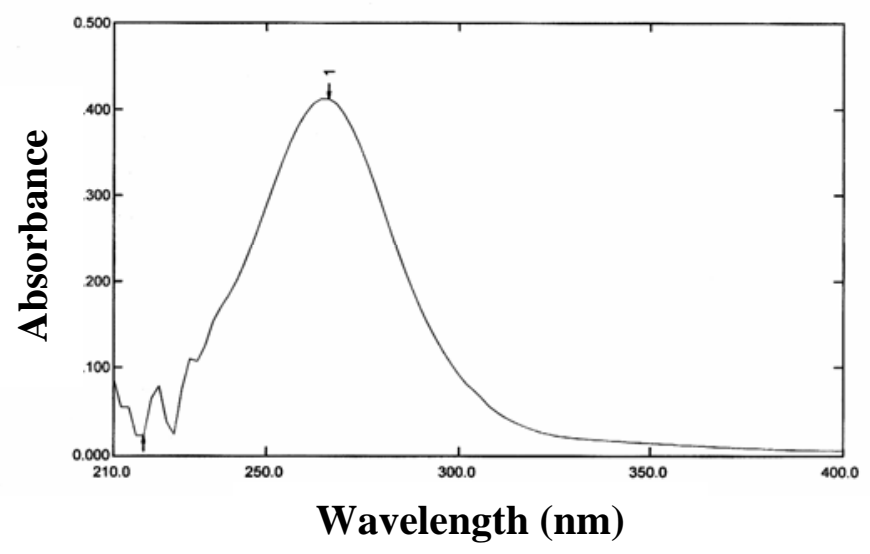

Figure (4): The U.V spectrum of $\left(2 \times 10^{-5} \mathrm{M}\right)$ of p-nitrobenzylidine p-toluenesulphonamide in absolute methanol

Table (3): The absorbance of different concentrations of compound (II) in absolute methanol at $(266 \mathrm{~nm})$

\begin{tabular}{|c|c|}
\hline Absorbance & Concentration (M) \\
\hline 0.119 & $6 \times 10^{-6}$ \\
\hline 0.141 & $7 \times 10^{-6}$ \\
\hline 0.156 & $8 \times 10^{-6}$ \\
\hline 0.209 & $1 \times 10^{-5}$ \\
\hline 0.411 & $2 \times 10^{-5}$ \\
\hline 0.584 & $3 \times 10^{-5}$ \\
\hline 0.779 & $4 \times 10^{-5}$ \\
\hline 0.974 & $5 \times 10^{-5}$ \\
\hline 1.147 & $6 \times 10^{-5}$ \\
\hline 1.312 & $7 \times 10^{-5}$ \\
\hline 1.432 & $8 \times 10^{-5}$ \\
\hline 1.664 & $9 \times 10^{-5}$ \\
\hline 1.793 & $1 \times 10^{-4}$ \\
\hline
\end{tabular}

The plot of the absorbance against the concentration (Fig. 5) gives a straight line obeying the Beer's Lambert law within a range of concentration (6 $\left.\times 10^{-6}-1 \times 10^{-4} \mathrm{M}\right)$, with determination limits $\left(1.8-30.4 \mu \mathrm{g} \mathrm{ml}{ }^{-1}\right)$ and $\mathrm{R}^{2}=$ (0.9979), RSD = (1.6\%).

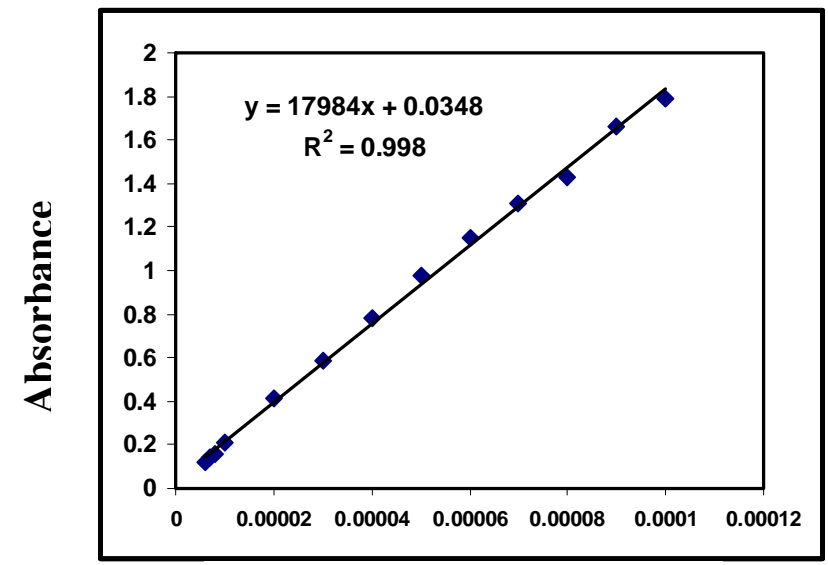

Concentration (M)

Figure (5): The relationship between absorbance and molar concentration for compound (II) 
The UV absorption spectrum of (1,6-dichlorobenzylidine ptoluenesulphonamide) (III) in absolute methanol (Fig. 6) shows absorption maxima at $(236 \mathrm{~nm})$ with $\varepsilon_{\max }=4122.2$ and a smaller peak at (304 nm) with $\varepsilon_{\max }=722.2$, (table 4$)$.

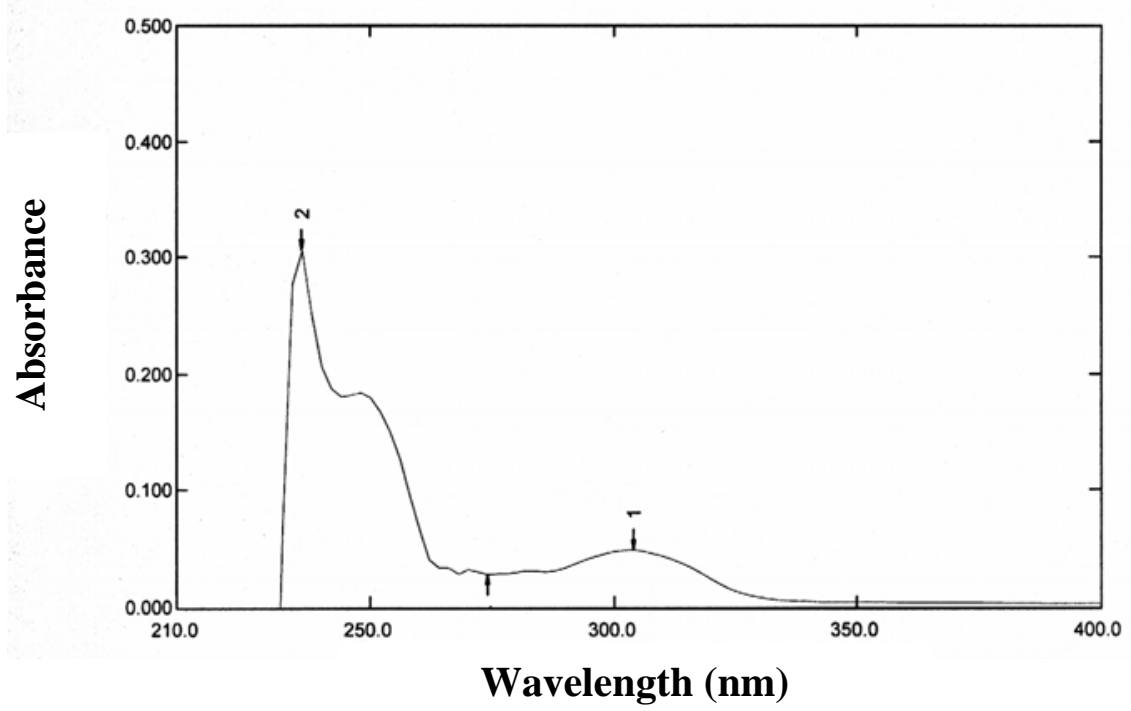

Figure (6): The U.V spectrum of $\left(7 \times 10^{-5} \mathrm{M}\right)$ of 1,6 - dichlorobenzylidine $\mathrm{p}$ toluenesulphonamide in absolute methanol

Table (4): Absorbances of different concentrations of (III) in absolute methanol at different wavelength

\begin{tabular}{|c|c|c|c|}
\hline \multicolumn{2}{|c|}{ At (236 nm) } & \multicolumn{2}{c|}{ At (304 nm) } \\
\hline Absorbance & Concentration (M) & Absorbance & Concentration (M) \\
\hline 0.100 & $8 \times 10^{-6}$ & 0.009 & $6 \times 10^{-6}$ \\
\hline 0.149 & $1 \times 10^{-5}$ & 0.011 & $7 \times 10^{-6}$ \\
\hline 0.182 & $2 \times 10^{-5}$ & 0.010 & $8 \times 10^{-6}$ \\
\hline 0.197 & $3 \times 10^{-5}$ & 0.011 & $1 \times 10^{-5}$ \\
\hline 0.194 & $4 \times 10^{-5}$ & 0.016 & $2 \times 10^{-5}$ \\
\hline 0.264 & $6 \times 10^{-5}$ & 0.022 & $3 \times 10^{-5}$ \\
\hline 0.306 & $7 \times 10^{-5}$ & 0.031 & $4 \times 10^{-5}$ \\
\hline 0.334 & $8 \times 10^{-5}$ & 0.036 & $5 \times 10^{-5}$ \\
\hline 0.371 & $9 \times 10^{-5}$ & 0.043 & $6 \times 10^{-5}$ \\
\hline 0.678 & $2 \times 10^{-4}$ & 0.049 & $7 \times 10^{-5}$ \\
\hline & & 0.065 & $9 \times 10^{-5}$ \\
\hline & & 0.119 & $2 \times 10^{-4}$ \\
\hline
\end{tabular}

The plot of the absorbance against the molar concentrations also resulted in a straight line obeying the Beer's Lambert law for the two bands (Fig.7), (Fig. 8).

Within a range of concentrations $\left(8 \times 10^{-6}-2 \times 10^{-4} \mathrm{M}\right)$, the determined limit was $\left(2.6-65.5 \mu \mathrm{g} \mathrm{ml}^{-1}\right), \mathrm{R}^{2}=(0.9906), \mathrm{RSD}=(1.1 \%)$. Also for the rang $\left(6 \times 10^{-6}-2 \times 10^{-4} \mathrm{M}\right)$ the determined limit was 
$\left(1.9-56.5 \mu \mathrm{g} \mathrm{ml}^{-1}\right), \mathrm{R}^{2}=0.9935, \mathrm{RSD}=(1.7 \%)$ at $(236 \mathrm{~nm})$ and $(304 \mathrm{~nm})$ respectively. The results indicate that the determination could be accomplished according to either the absorption peak maximum $\lambda=236$ $\mathrm{nm}$ or $\lambda=304 \mathrm{~nm}$ taking into consideration that the second peak $\lambda=304$ $\mathrm{nm}$ to be more preferable.

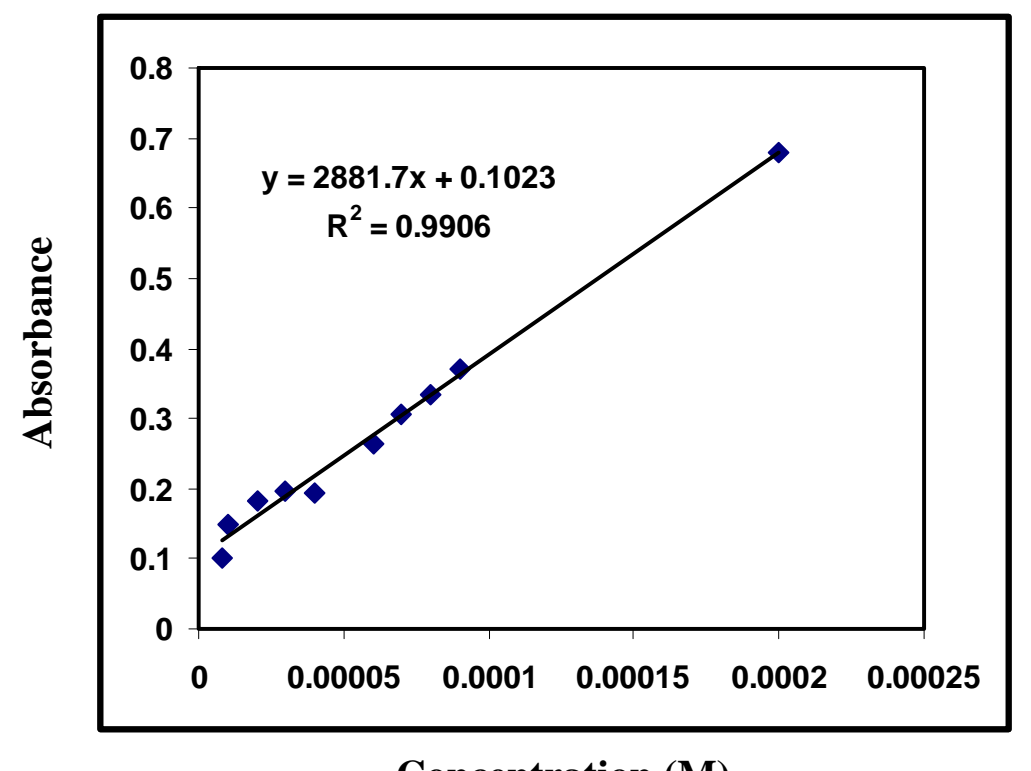

Concentration (M)

Figure (7): The relationship between absorbance and molar concentration for compound (III) at (236 $\mathrm{nm})$

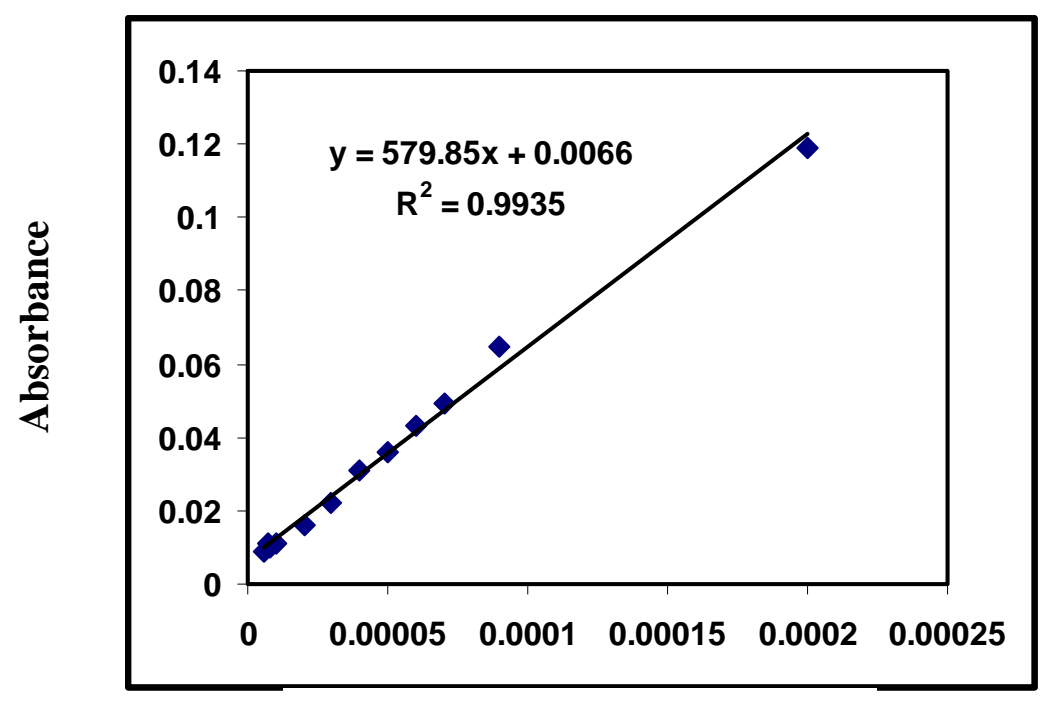

Concentration (M)

Figure (8): The relationship between absorbance and molar concentration for compound (III) at (304 $\mathrm{nm})$

The UV absorption spectra for (3,4-dimethoxybenzylidine ptoluenesulphonamide) (IV) in absolute methanol was recorded and shows three absorption peak maxima at $(236 \mathrm{~nm}),(274 \mathrm{~nm})$ and $(308 \mathrm{~nm})$, (Fig.9), (table 5). 


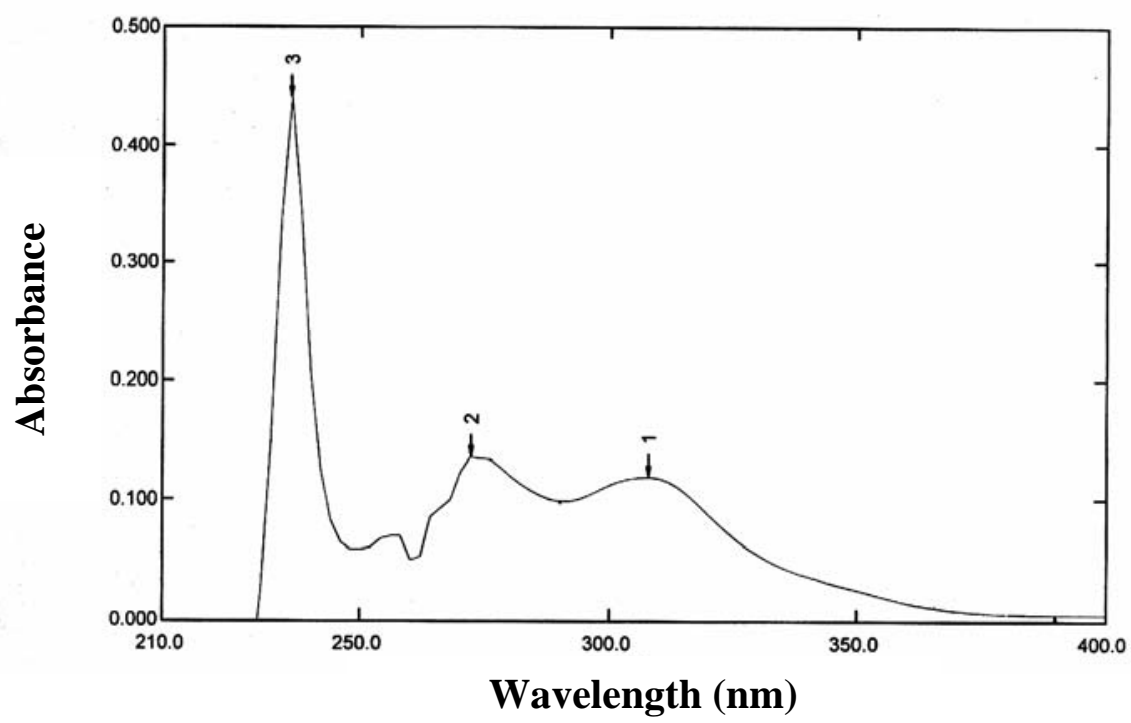

Figure (9): The U.V spectrum of $\left(6 \times 10^{-5} \mathrm{M}\right)$ of 3,4- dimethoxybenzylidine ptoluene- sulphonamide in absolute methanol

Table (5): The absorbance of different concentrations of compound (IV) in absolute methanol at different wavelength

\begin{tabular}{|c|c|c|c|c|c|}
\hline \multicolumn{2}{|c|}{ At (236 nm) } & \multicolumn{2}{c|}{ At (274 nm) } & \multicolumn{2}{c|}{ At (308 nm) } \\
\hline Abs. & Conc. (M) & Abs. & Conc. (M) & Abs. & Conc. (M) \\
\hline 0.068 & $6 \times 10^{-6}$ & 0.018 & $6 \times 10^{-6}$ & 0.014 & $6 \times 10^{-6}$ \\
\hline 0.046 & $9 \times 10^{-6}$ & 0.025 & $9 \times 10^{-6}$ & 0.018 & $7 \times 10^{-6}$ \\
\hline 0.151 & $2 \times 10^{-5}$ & 0.030 & $2 \times 10^{-5}$ & 0.020 & $8 \times 10^{-6}$ \\
\hline 0.216 & $3 \times 10^{-5}$ & 0.058 & $3 \times 10^{-5}$ & 0.021 & $9 \times 10^{-6}$ \\
\hline 0.393 & $5 \times 10^{-5}$ & 0.079 & $4 \times 10^{-5}$ & 0.025 & $1 \times 10^{-5}$ \\
\hline 0.440 & $6 \times 10^{-5}$ & 0.105 & $5 \times 10^{-5}$ & 0.032 & $2 \times 10^{-5}$ \\
\hline 0.531 & $7 \times 10^{-5}$ & 0.135 & $6 \times 10^{-5}$ & 0.053 & $3 \times 10^{-5}$ \\
\hline & & 0.146 & $7 \times 10^{-5}$ & 0.077 & $4 \times 10^{-5}$ \\
\hline & 0.182 & $8 \times 10^{-5}$ & 0.095 & $5 \times 10^{-5}$ \\
\hline & 0.207 & $9 \times 10^{-5}$ & 0.119 & $6 \times 10^{-5}$ \\
\hline & & 0.231 & $1 \times 10^{-4}$ & 0.132 & $7 \times 10^{-5}$ \\
\hline & & 0.573 & $2 \times 10^{-4}$ & 0.160 & $8 \times 10^{-5}$ \\
\hline & 0.769 & $3 \times 10^{-4}$ & 0.176 & $9 \times 10^{-5}$ \\
\hline & & & & 0.202 & $1 \times 10^{-4}$ \\
\hline & & & & 0.452 & $2 \times 10^{-4}$ \\
\hline & & & & & $3 \times 10^{-4}$ \\
\hline
\end{tabular}

The plot of the absorbance against the molar concentration result in a straight line obeying the Beer's Lambert law for all the three peaks (Fig. 10) (Fig. 11) (Fig. 12), within a range of concentration $\left(6 \times 10^{-6}-7 \times 10^{-5}\right.$ $\mathrm{M}),\left(6 \times 10^{-6}-3 \times 10^{-4} \mathrm{M}\right)$ and $\left(6 \times 10^{-6}-3 \times 10^{-4} \mathrm{M}\right)$, determination limit $\left(2.9-34.2 \mu \mathrm{g} \mathrm{ml}^{-1}\right),\left(2.9-146.7 \mu \mathrm{g} \mathrm{ml}^{-1}\right)$ and $\left(2.9-146.7 \mu \mathrm{g} \mathrm{ml} \mathrm{m}^{-1}\right), \mathrm{R}^{2}=$ (0.9930), (0.9906) and (0.9954), RSD = (2.8\%), (2.5\%) and (1.3\%) and $\varepsilon_{\max }=(7585.7),(2085.7) \&(1885.7)$ at $(236 \mathrm{~nm}),(274 \mathrm{~nm})$ and $(308 \mathrm{~nm})$, respectively. 


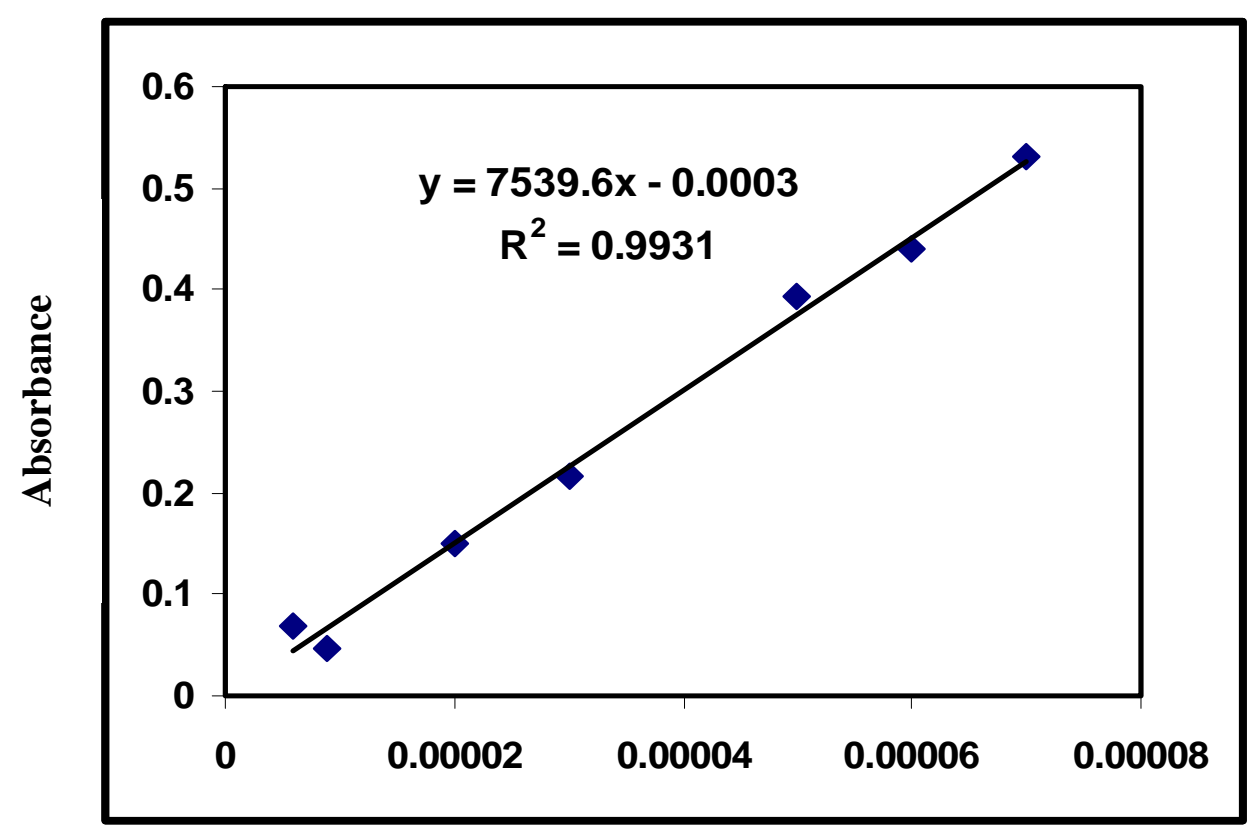

Concentration (M)

Figure (10): The relationship between absorbance and molar concentration for compound (IV) at (236 $\mathrm{nm})$

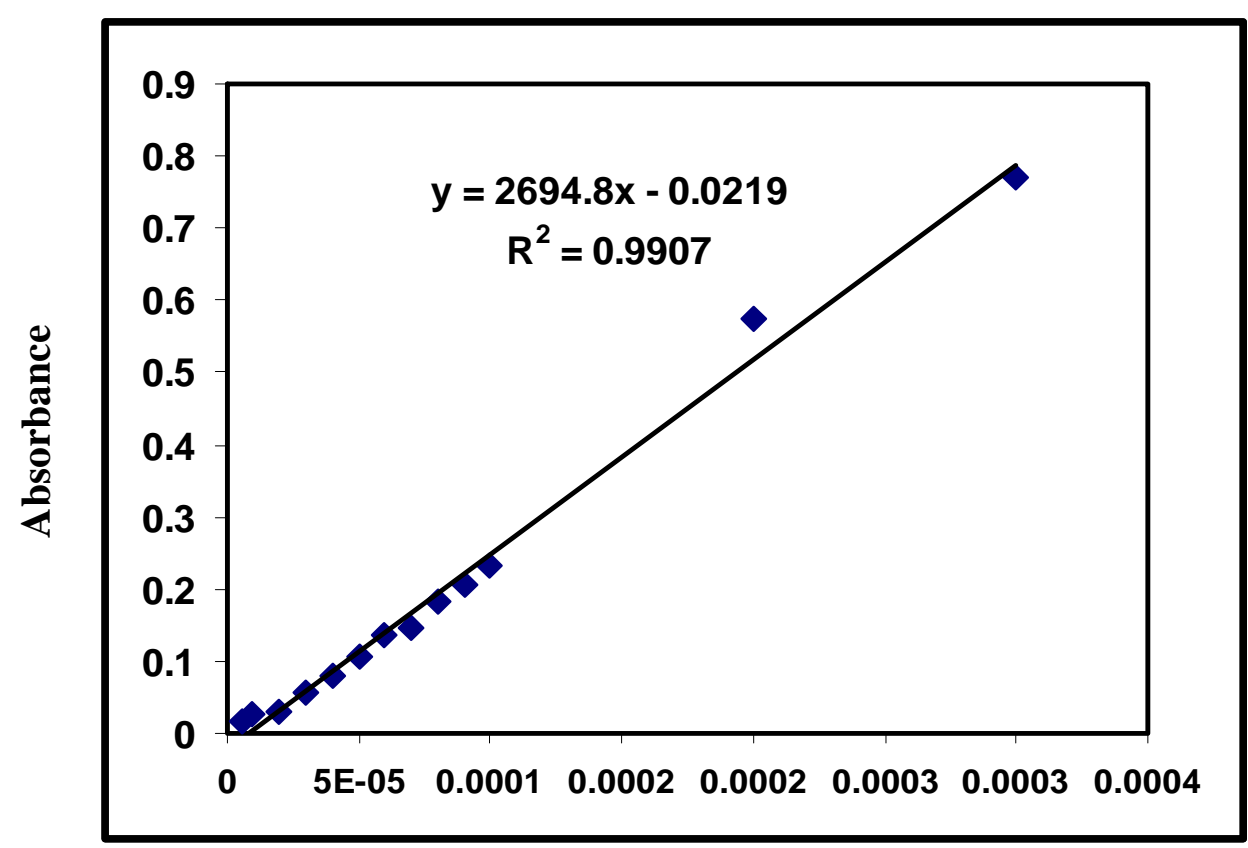

Concentration (M)

Figure (11): The relationship between absorbance and molar concentration for compound (IV) at (274 $\mathrm{nm})$ 


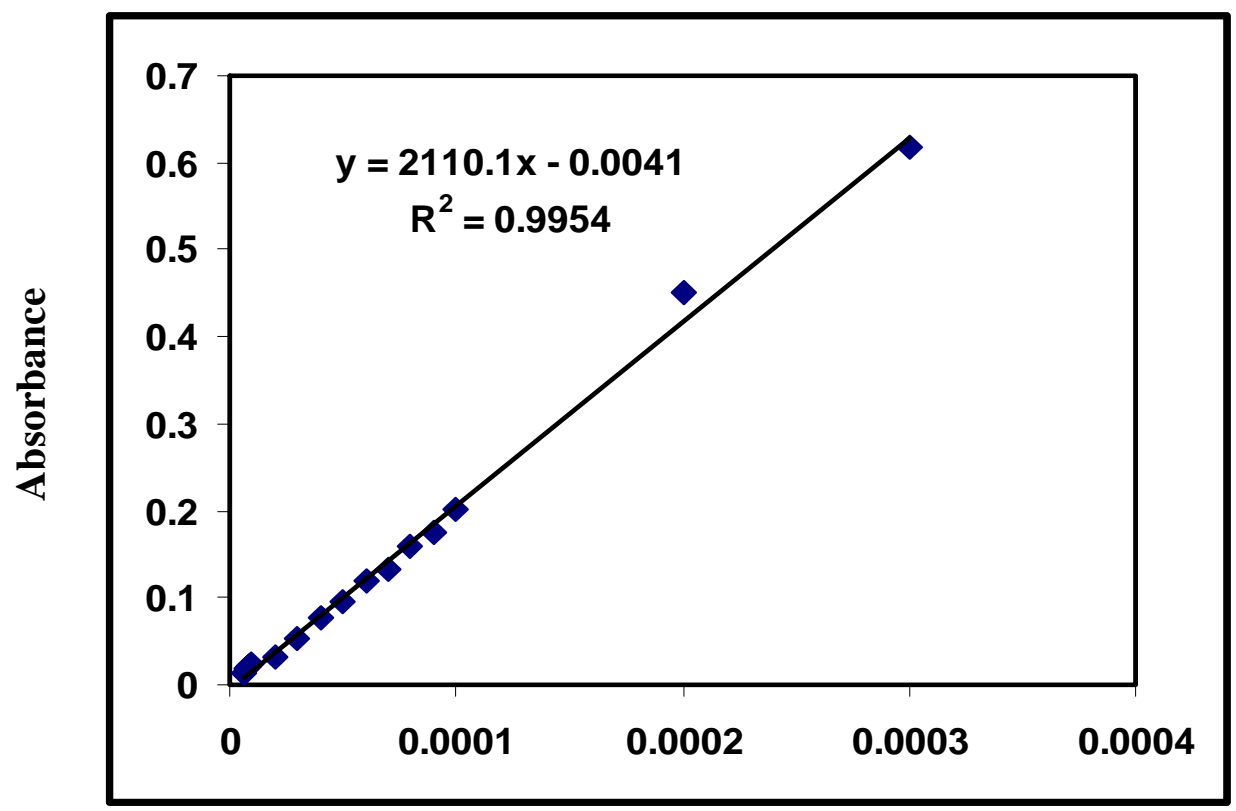

Concentration (M)

Figure (12): The relationship between absorbance and molar concentration for compound (IV) at (308 $\mathbf{~ m})$

From these results we can conclude that in the U.V spectrum of all the compounds (I-IV) show $n \rightarrow \pi^{*}$ and $\pi \rightarrow \pi^{*}$ electronic transition.

The compound (I) appear the wavelength at $236 \mathrm{~nm}$ while the compound (II) give the higher wavelength at $266 \mathrm{~nm}$ due to increase the conjugated of $\pi$ bond in the presence of nitro group, where as compound (III) has two bands at $236 \mathrm{~nm}$ and $304 \mathrm{~nm}$ related to the two atom of chlorine participating in resonance effect with the aromatic ring, in addition the compound (IV) appears three bands at 236nm, 274nm, and $304 \mathrm{~nm}$ due to the activating group at 3,4 position of the ring.

It is clear that the peak of every $\lambda_{\max }$ for all compounds (I-IV) increased with concentration as shown in figure (13), (14), as well as the good values of $\mathrm{R}^{2}$ and $\mathrm{RSD}$ for all compounds at the range of concentration $\left(6 \times 10^{-6}-3 \times 10^{-4} \mathrm{M}\right)$, at last the values of $\varepsilon_{\max }$ for all compound which is agreement with the electronic transition.

So that the study is successfully for trace amounts of these Schiff bases compounds. 
Amel G. Abed

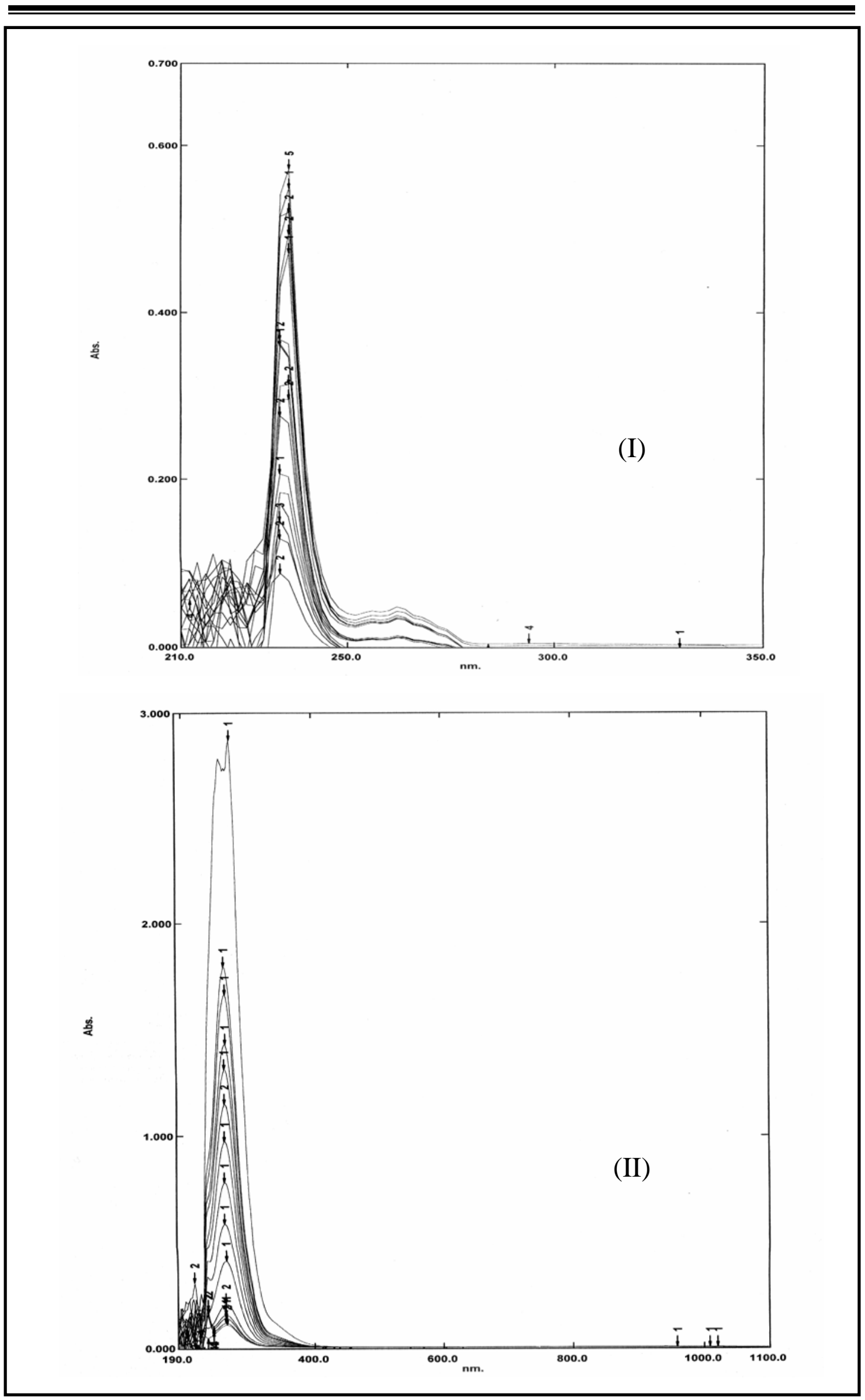

Figure (13): The U.V spectrum of different concentration of (I) and (II). 


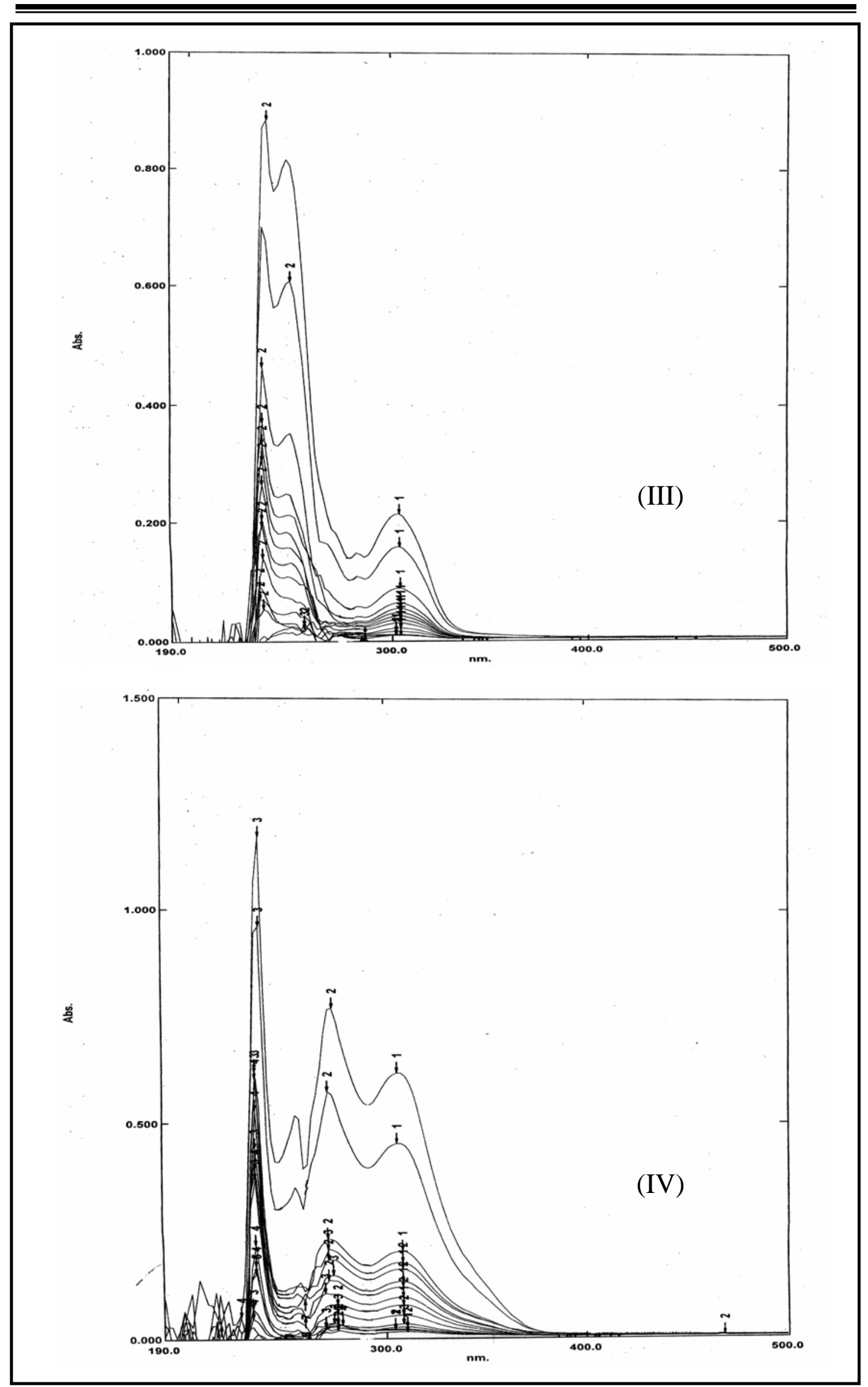

Figure (14): The U.V spectrum of different concentration of (III) and (IV). 


\section{References}

(1) S. Rao, A.S. Mittra, J. Indian. Chem. Soc., 55(1978), 420-422.

(2) O. Banerjea, "Coordination chemistry 20", Pergamon Press, IUPAC, Oxford, New York, (1980), pp. 15-26, 141-148.

(3) A.K. Mittal, O.P. Singhal, J. Indian. Chem. Soc., 63(1986), 759760.

(4) S.J. Yan, W.H. Burton, P.L. Chien, C.C. Cheng, J. heterocycl. Chem., 15(1978), 297-300.

(5) S.K.Y. Al-Azawi, Ph.D. Thesis Mosul University, (2006).

(6) M.G. Derebe, V.J.T. Raju and N. Retta, Chemical Society of Ethiopia, 16 (2002), 53-54.

(7) A.Afkhami, F.Khajavi and H.Khanmohammadi, J. Chem. Eng. Data, 54 (2009), 866-870.

(8) J. T. Stewart, G.S. Yoo, Journal of Pharmaceutical Sciences, 77 (2006), 452-454.

(9) K. Siddappa, M. Mallikarjum, P.T. Reddy, M. Tambe, Ecl. Quin., 33(2008), 41-46.

(10) S. Y. SH. Zebary, Higher Diploma Thesis, Mosul University, (2010).

(11) A.K. Abdul-Hussain, M. Sc. Thesis, Baghdad University, (1986).

(12) E.K. Ebrahim, M. Sc. Thesis, Baghdad University, (1983).

(13) A.A. Sultan, M.Sc. Thesis, Basrah University, (1982).

(14) S. A. Said, Raf. J. Sci., 17 (2006), 5-10.

(15) G. Mwkut, Synlett Synlett, (2003), 2097-2098.

(16) M.A. El. Machraby, A. E. Khalafalla, M. E. Hassan and H.A. Soleimani, J. India Chem. Soc., (1986), LXIII, 910-913.

(17) A. M. T. D. P. V. Cabral, A. M. A. R. Gonsalves and T. M. V. D. P. Melo, Molecules, (1993), 3, 60-63. 